\title{
CONTROLADOR AVANÇADO PARA UNIFORMIZAÇÃO DA VAZÃO DE UM DOSADOR HELICOIDAL DE FERTILIZANTES
}

ANDREI GRESPAN (IC), ANGEL P. GARCIA (PQ), ANTÔNIO H. B. RIBEIRO (PG), FABRÍCIO T. SOARES (PG).

\section{Resumo}

O controle da aplicação de fertilizantes visando à otimização da operação é uma parte essencial da agricultura de precisão e traz consigo a economia de insumos, aumento da produção e preservação do solo. Os dosadores atuais possuem uma característica oscilatória na taxa de aplicação, comprometendo assim a uniformidade de distribuição do fertilizante. Este trabalho teve por objetivo a validação de um sistema de controle cíclico para o acionamento de um dosador helicoidal de fertilizantes.

Palavras Chave: Adubadora, controle não linear, agricultura de precisão.

\section{Introdução}

O dosador helicoidal de fertilizantes convencional é o mais importante componente em adubadoras agrícolas, sendo responsável pela distribuição do fertilizante. Esta distribuição apresenta variação do fluxo de massa instantâneo durante um ciclo de rotação do helicoide, consequência de seu princípio de funcionamento. Embasados nesta característica não desejável, GARCIA et al. 2012 trabalharam na compreensão do fenômeno e na parametrização de modelos para o sistema. Este trabalho tem por objetivo a validação de sistemas de controles propostos para a regulagem da taxa de aplicação através de um controlador não linear que atua em um motor elétrico de corrente contínua modificando a velocidade angular durante sua operação.

\section{Resultados e Discussão}

A seguir o modelo proposto para o funcionamento do helicoide do dosador que correlaciona a velocidade angular do eixo de acionamento, as características geométricas de fabricação do helicóide e a eficiência de transporte com a vazão instantânea.

$$
\dot{m}_{i}(t)=K(A p \eta \rho) \dot{\theta}(t)\left\{\frac{1}{K}+[f \operatorname{sen}(\theta(t))]\right\}
$$

Equação 1. Modelo proposto por GARCIA et al. 2012, que rege o funcionamento do helicoide.

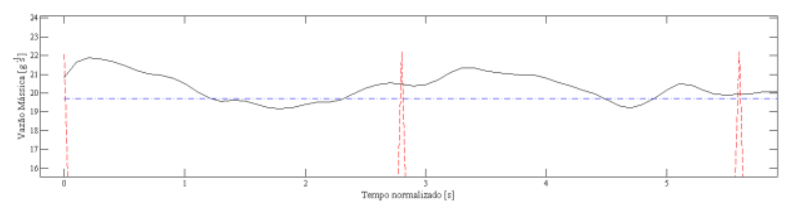

Figura 1. Vazão experimental, para a velocidade angular média do eixo de 3,7 rad/s.
A comparação entre os coeficientes de variação (CV), medidos para os valores de vazão instantânea do dosador sob velocidade angular constante e com a associação do controlador, para diferentes valores de Vm são apresentados na Figura 2 a seguir.

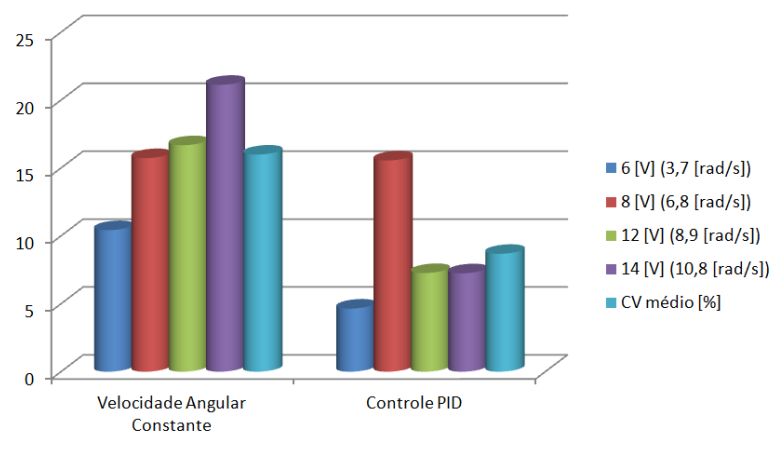

Figura 2. Coeficientes de variação de vazão mássica, sob velocidade angular constante e com a atuação do controlador.

\section{Conclusões}

Os testes provaram que o sistema de controle proposto obteve um desempenho satisfatório, reduzindo o CV médio da vazão de 15,99 \% para $8,68 \%$ e mantendo 0 desempenho para diferentes valores de $\mathrm{Vm}$, se adaptando às condições requeridas para a utilização em AP.

\section{Agradecimentos}

Ao programa CNPq/PIBIC e aos membros do Laboratório de Instrumentação e Controle da FEAGRI pelo apoio durante a execução deste trabalho.

GARCIA, A. P.; CAPPELLI, N. L.; UMEZU, C. K. Auger-type granular fertylizer distributor: matemathical model and dynamic simulation. Engenharia Agrícola, v. 32, n. 1, p. 151-163, fev. 2012. 